\title{
Artes marciais na Educação Infantil: desafios e possibilidades
}

\author{
Martial arts in early Childhood Education: \\ challenges and possibilities
}

\section{Artes marciales en la Educación Infantil: desafíos y posibilidades}

LEANDRO PEREIRA ARAÚJO*

Universidade Do Estado de Santa Catarina, Florianópolis- SC, Brasil.

LARISSA CERIGNONI BENITES ${ }^{* *}$

Universidade Do Estado de Santa Catarina, Florianópolis- SC, Brasil.

ELISÂNGELA VENÂNCIO ANANIAS ${ }^{* * * *}$

Universidade Do Estado de Santa Catarina, Florianópolis- SC, Brasil.

VIVIANE PREICHARDT DUEK

Universidade Do Estado de Santa Catarina, Florianópolis- SC, Brasil.

\begin{abstract}
RESUMO: O relato descreve uma experiência de ensino com um grupo de crianças de cinco e seis anos, apontando desafios e possibilidades da inserção de Artes Marciais nas aulas de educação física infantil. As intervenções indicaram que a aprendizagem desse conteúdo foi motivante, contribuindo para desmistificar ideias relacionadas à violência e gênero. Concluímos que o ensino das lutas é possível,
\end{abstract}

* Licenciado em Educação Física pela Universidade do Estado de Santa Catarina. E-mail:<profleandrojj@gmail.com>.

* Licenciada em Educação Física, Mestre e Doutora em Ciência da Motricidade pela Universidade Estadual Paulista Júlio de Mesquita Filho. Atualmente é professora adjunta na Universidade do Estado de Santa Catarina, vinculada ao Centro de Ciências da saúde e do esporte. E-mail: <lari.benites@gmail.com>.

*** Doutora em Ciências da Motricidade pela Universidade Estadual Paulista Júlio de Mesquita Filho. Atualmente é professora colaboradora na Universidade do Estado de Santa Catarina, vinculada ao Centro de Ciências da saúde e do esporte. E-mail: <elisangelavenancio@hotmail.com>.

**** Doutora em Educação pela Universidade Federal do Rio Grande do Norte e Mestre em Educação pela Universidade Federal de Santa Maria. Atualmente é professora adjunta na Universidade do Estado de Santa Catarina, vinculada ao Centro de Ciências da saúde e do esporte. E-mail: <vividuek@hotmail.com>. 
mediante adequações do espaço e materiais, de modo a respeitar as características da instituição e do público, especialmente as crianças.

Palavras-chave: Artes marciais. Educação física. Educação infantil.

ABSTRACT: The report describes a teaching experience with a group of five and six year olds, pointing out challenges and possibilities of the insertion of Martial Arts in children's physical education classes. The interventions indicated that learning this content was motivating, contributing to demystify ideas related to violence and gender. We conclude that the teaching of martial arts is possible, by means of space and material adjustments, in order to respect the characteristics of the institution and the audience, especially the children.

Keywords: Martial Arts. Physical Education. Early childhood education.

RESUMEN: El relato describe una experiencia docente con un grupo de niños de cinco y seis años, señalando los desafíos y las posibilidades de insertar las artes marciales en las clases de educación física infantil. Las intervenciones indicaron que el aprendizaje de este contenido fue motivador, contribuyendo a desmitificar ideas relacionadas con la violencia y el género. Concluimos que la enseñanza de las luchas es posible mediante ajustes de espacio y materiales, de modo a respetar las características de la institución y del público, especialmente los niños.

Palabras clave: Artes marciales. Educación física. Educación Infantil.

\section{Introdução}

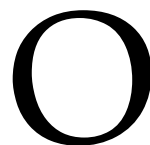

presente relato discute a inserção das lutas nas aulas de educação física a partir de uma experiência que buscou tematizar esse elemento da cultura corporal com um grupo de crianças de cinco a seis anos, em uma instituição de educação infantil pertencente à rede municipal de Florianópolis/SC. Trata-se de uma proposta desenvolvida no contexto do Estágio Curricular Supervisionado $I^{1}$, no curso de Licenciatura em Educação Física do Centro de Ciências da Saúde e do Esporte, da Universidade do Estado de Santa Catarina.

As Lutas, enquanto manifestação da cultura corporal de movimento, apresentam algumas características de enfrentamento físico direto entre pessoas, por meio de regras claramente estipuladas, além de importância histórica e cultural com objetivos voltados à oposição entre os indivíduos, com ações de caráter simultâneo e imprevisível. As Lutas 
também compreendem questões históricas e de caráter filosófico, que ainda permeiam esta prática nos dias atuais. Exemplo disso pode ser observado nos trajes, nas formas de saudação, na organização do ensino de algumas modalidades, na importância delas em algumas sociedades, dentre outros (RUFINO, 2014).

Autores como Rufino (2014), Maduro (2015), Cirino, Pereira e Scaglia (2013), Nascimento e Almeida (2007), entre outros, afirmam que, embora a luta compreenda um amplo leque de possibilidades pedagógicas e educacionais, o seu ensino no contexto escolar ainda enfrenta desafios. Um deles refere-se à dificuldade no ensino desse conteúdo por professores que não tiveram formação específica ou experiências prévias com essa prática corporal, o que acaba gerando resistências, sobretudo entre os professores, por acreditarem que é preciso ser um especialista em alguma modalidade de luta para poder ensiná-la.

Segundo Pereira et al (2015) parte dessa dificuldade é decorrente do paradigma vigente no ensino das lutas na escola, assentado em aulas centradas na técnica e no educador, que priorizam a execução correta dos movimentos com a reprodução do gesto mecânico pelo educando, priorizando-se, em geral, uma única modalidade de luta (na maioria das vezes a modalidade que o educador era praticante).

Outra dificuldade que contribui para a pouca presença das lutas nos currículos da educação física, diz respeito à representação de que aprendizagem desse conteúdo venha estimular atitudes agressivas e/ou comportamentos violentos entre seus praticantes. Nesse sentido, Olivier (2000), afirma que a violência não pode ser pensada como resultado de um único fator, uma vez que ela é resultado de múltiplas determinações. Assim, a presença de comportamentos violentos vai além da prática da luta, uma vez que ela está presente na sociedade e é inerente às relações sociais, indicando formas de se comunicar em situações de conflito, de ameaça e de insegurança. Ainda segundo esse autor, quando bem sistematizadas e conduzidas, essas atividades auxiliam as crianças a controlar as reações violentas que podem acontecer no cotidiano escolar.

A educação física no contexto escolar tem como objetivo tematizar os diferentes conteúdos da cultura corporal, dentre os quais, as lutas. Nascimento e Almeida (2007) apontam que o componente das lutas pode abarcar aspectos da autonomia, criticidade, emancipação e construção de conhecimentos significativos nas aulas de educação física escolar. Ademais, Rufino e Darido (2009) destacam o potencial educativo dessa atividade, visto que ela permite abordar temas que envolvem o ensino dos fundamentos das lutas, seus aspectos históricos e culturais, além de questões éticas e o desenvolvimento de valores como respeito e cooperação entre os praticantes.

Partindo desse entendimento, assumimos o desafio de inserir o conteúdo de lutas nas aulas de educação física na educação infantil, no intuito de promover o acesso e ampliar a compreensão das crianças acerca dessa prática corporal, enquanto elemento da cultura. Portanto, este relato descreve uma experiência de ensino que tematizou as lutas na 
educação infantil, apontando desafios e possibilidades da inserção desse conteúdo nas aulas de educação física nesta etapa da educação básica.

Assim sendo, a construção desse relato de experiência fundamentou-se, para além da memória sobre situações marcantes vividas no cotidiano junto às crianças da educação infantil, em registros sistemáticos (diários de aula) realizados pelo estagiário durante o período das intervenções. Também subsidiaram essa produção fotos, filmagens, planos de aula e de trabalho e relatório final de estágio, os quais permitiram avaliar o processo pedagógico fazendo os ajustes necessários, bem como resgatar os detalhes e momentos importantes na experiência relatada a seguir.

\section{Breve contextualização da experiência}

Este relato é um registro das experiências docentes desenvolvidas no contexto do Estágio Curricular Supervisionado I, em um Núcleo de Educação Infantil Municipal (Neim) pertencente à rede municipal de ensino de Florianópolis/SC, localizado na porção continental da cidade, que atende aproximadamente 160 crianças de 2 a 5 anos, distribuídas em oito grupos, sendo quatro no período matutino e quatro no período vespertino.

A instituição conta com um quadro funcional constituído pelas professoras regentes, auxiliares de sala², diretora, coordenadora pedagógica, professora de educação física/ supervisora de estágio, além de funcionárias responsáveis pelo serviço administrativo de limpeza e alimentação.

Sua estrutura física e material conta com quatro salas de aula amplas, sendo que duas contam com banheiro individual e as outras duas com banheiro conjugado. Dispõe, ainda, de biblioteca, sala de direção, sala de professores, sala de supervisão, depósito, banheiro de adulto, lavanderia, cozinha com dispensa, hall de entrada no qual localiza-se um corredor com armários onde são armazenados os materiais da educação física, mini quadra de concreto, além de um parque arborizado e com brinquedos variados, tais como: um gira-gira, quatro balanços de pneus, uma casinha, um túnel de pneu e um de concreto, playground com casinha e escorregador, um trepa-trepa de pneu, quatro gangorras. A instituição ainda dispõe de materiais como aparelho de som e aparelho de DVD, televisão e caixa de som, tapetes e almofadas disponíveis para o uso nas aulas. Entre os materiais disponíveis para as aulas de educação física, encontramos bolas de tênis, bolas de borracha, bolas de plástico, cordas, arcos, chinelão, túnel de tecido, colchonetes, pneus, raquetes de frescobol, boca do palhaço, dentre outros.

As aulas de educação física foram desenvolvidas com um grupo de 25 crianças entre 5 e 6 anos, no período vespertino, duas vezes por semana, com duração de uma hora e quinze cada aula, no período de dez semanas. 
O ponto de partida para a construção da nossa proposta de ensino foram as informações levantadas no período de observação, em que procuramos conhecer e analisar as instalações, os materiais, o planejamento e desenvolvimento das aulas pela professora de educação física, além do projeto político pedagógico da unidade. Mediante esse levantamento e aproximação inicial com o campo de estágio, elaboramos um plano de trabalho, composto de conteúdos, objetivo geral e objetivos específicos, procedimentos didático-metodológicos, espaços e recursos materiais, avaliação, além de um cronograma das intervenções.

De modo geral a tematização das lutas nas aulas de educação física buscou contemplar conteúdos relativos às características das lutas, histórico e conceitos, a vivência dos princípios e fundamentos nesta prática corporal e a formação de valores e atitudes. Portanto, foram abordados temas referentes à segurança, questões éticas e morais, além de atitudes de respeito e colaboração na prática das atividades propostas.

As intervenções foram organizadas e desenvolvidas por meio de jogos e brincadeiras adaptados para o contexto da educação infantil, o que implicou a adequação dos espaços e materiais disponíveis na instituição, além do cuidado com relação a questões de risco intrínsecas na prática das lutas.

Para o processo de avaliação e registo foram realizadas as rodas de conversa inicial e final com as crianças e todos os momentos foram registrados por meio de fotografia, filmagens e relatos semanais de episódios marcantes ocorridos nas aulas, os quais subsidiaram o relato a seguir.

\section{Descrevendo e refletindo as experiências}

Qual professor, ao repreender duas crianças que se agarravam ou empurravam, não obteve como resposta essa afirmação, geralmente dita de maneira inocente: "Estamos só brincando..."? (NEIRA, 2014, p. 90).

A cena acima descrita, comum no universo escolar, reflete a ideia de que as brincadeiras de lutas fazem parte da cultura lúdica infantil, constituindo-se em práticas corporais que possuem símbolos e significados revelados na experiência infantil. Portanto, ao empurrar, puxar, chutar ou bater, as crianças estão ressignificando corporalmente movimentos que, embora possuam sentidos e significados anteriores às próprias ações, são reinterpretados e reinventados na experiência infantil. Desse modo, em nossa prática buscamos abordar as lutas na educação infantil no sentido de valorizar o olhar da própria criança acerca dessa prática corporal, conforme preconizado por Farias, Wiggers e Viana (2014).

Com base nesse princípio, as aulas sempre iniciavam com uma roda de conversa com o objetivo de levantar os saberes e experiências prévias das crianças sobre o tema. 
A pergunta norteadora foi: “O que é luta?". Diante disso, as crianças realizavam movimentos referentes às lutas e expressavam o seu pensamento: "passa na televisão e a gente assiste", "meu pai luta", "eu luto com o meu pai". Esse momento foi importante, pois envolveu a construção de conceitos sobre essa atividade, reafirmando a importância de uma intervenção pedagógica no sentido de ampliar as noções. Ainda com o propósito de contextualizar as lutas junto às crianças, utilizamos vídeos que remetiam aos movimentos presentes nas diferentes modalidades de lutas de agarre ${ }^{3}$, ou seja, aquelas que têm um contato contínuo com o seu oponente (projeções, rolar, agarrar, imobilizar, pegar, desequilibrar etc.).

Após a exposição dos vídeos o estagiário lançava diversos questionamentos às crianças: “O que vimos?", “O que estão fazendo?”, "Que movimentos estão realizando”, "Estão lutando ou brigando?", “Existe diferença entre lutar e brigar?” etc. Essa problematização inicial possibilitou a associação pelas crianças de que "luta tem regra", "luta ganha medalha", "luta não é briga", despertando o desejo em vivenciar esse conteúdo nas aulas. Também demonstraram conhecimento sobre algumas das modalidades de lutas esportivas e seus lutadores, muitas dessas difundidas pela mídia, ampliando a popularidade e o acesso facilitado pelas crianças, uma vez que estão disponíveis na televisão aberta. De acordo com Maduro (2015), as lutas vêm sendo vinculadas diariamente pelos meios de comunicação sob o olhar do esporte-espetáculo, como os eventos de $\mathrm{MMA}^{4}$, promovendo argumentos que podem ser utilizados para a sua rejeição no ambiente escolar.

Esse momento foi importante para ampliar a compreensão das crianças sobre o tema das lutas e para desmistificar a relação entre luta e violência. Perguntou-se às crianças, por exemplo, se era correto bater ou machucar o colega e elas também puderam expressar o seu pensamento sobre situações violentas e lutas, diferenciando essas duas manifestações. Sobre isso, Rufino (2014) afirma que a diferenciação entre luta e briga é essencial, uma vez que se trata de ações distintas pela sua natureza. Enquanto a luta apresenta regras e atitudes de respeito entre os praticantes, além de uma organização social, a briga, por sua vez, não apresenta regras, é desorganizada, representando uma forma violenta de resolver conflitos, por meio de ações não éticas e de desrespeito, diferindo, assim, das lutas.

Convém destacar que ao longo das aulas as questões de gênero estiveram presentes, com uma diferenciação entre meninos e meninas, sendo que algumas destas não demonstravam interesse em participar das aulas, afirmando que "menina não luta" e que isso é "coisa de menino". A fim de mediar esse conflito, o estagiário buscou refletir com as crianças sobre a participação/presença das mulheres em diferentes esportes, inclusive nas lutas. Essa reflexão foi feita na roda final, na avaliação da aula e também durante as atividades. Uma estratégia elaborada pelo estagiário foi a de montar duplas ora de menino com menino, ora de menina com menina e ora duplas mistas, mostrando que as meninas também poderiam participar, bem como despertar o prazer pelas lutas. Nessa experiência o estímulo, através de conversas, além de jogos e brincadeiras, contribuiu pra 
ampliar a participação nas atividades. Também foram retomadas imagens dos vídeos em que tanto homens, quanto mulheres e crianças apareciam lutando em diversos ambientes (academias, clubes, jogos olímpicos etc.). Segundo Rufino (2014), o gênero é uma questão que requer muita atenção do professor no ensino das lutas, uma vez que esta prática corporal encontra-se impregnada pela ideia de que "menina não pode lutar", cabendo ao professor e toda comunidade escolar o emprego de estratégias com o objetivo de problematizar e desmistificar essa representação.

Metodologicamente, as primeiras atividades propostas envolveram movimentos da ginástica natural (saltos, rolamentos, quedas, projeções) presentes em diferentes modalidades de lutas. As crianças eram estimuladas a imitar movimentos dos animais, explorando o nível alto, médio e baixo (onça, aranha, jacaré etc.). Para tanto, o espaço foi adaptado e no lugar do tatame foi construída uma "arena" com tapetes, colchonetes e almofadas existentes na instituição. A adequação do espaço, segundo RUFINO (2014) e MADURO (2015) é um dos princípios básicos a ser considerado no ensino desse conteúdo, abrangendo questões de infraestrutura, qualidade dos materiais, além de local apropriado para esta prática o qual deverá ser amplo, sem a presença de quinas e colunas, espelhos e desníveis no piso que possam colaborar para possíveis acidentes.

Nas aulas subsequentes foram propostas atividades no intuito de explorar aspectos históricos, conceituais e de condutas, bem como a vivência de elementos presentes nas lutas, como equilíbrio, projeções, imobilizações, quedas e rolamentos. Para tanto, realizamos alguns jogos e brincadeiras com as crianças, tais como "veste e veste", "pega e puxa", "a bola é minha" e "pega na cabeça". Importante destacar que a utilização de jogos para a sistematização do conteúdo das lutas permite criar oportunidades para a criança vivenciar situações lúdicas diversificadas, apresentando-se como uma estratégia adequada ao estágio de desenvolvimento em que ela se encontra (CIRINO, PEREIRA; SCAGLIA, 2013).

Na brincadeira "veste e veste" as crianças deveriam auxiliar o colega a vestir o kimono e depois vestir a si mesmo. Para tanto, o grupo foi organizado em duas colunas que, ao sinal do estagiário, uma criança de cada coluna deveria se deslocar em direção àquela posicionada no outro lado da 'arena', auxiliando-a a vestir o kimono. Depois que todos cumpriram a tarefa, invertiam-se os papéis. Terminada essa etapa, inicia-se a mesma tarefa, agora realizada de forma individual, em que cada criança deveria vestir-se sozinha. Após a atividade, era feita uma roda de conversa entre o estagiário e as crianças sobre o que fizeram na aula, o que sentiram e o que aprenderam ao realizar as brincadeiras. Nesta atividade foi possível discutir questões conceituais e históricas das lutas, de modo que as crianças conheceram o kimono e as partes que o compõem enquanto vestimenta utilizada em determinadas lutas como o judô, o karatê e o jiu-jitsu brasileiro. Por meio desta vivência foi possível abordar temas relacionados à aprendizagem e respeito às regras, enquanto um valor presente nas lutas, à ampliação do sentido ético de vencer e perder, bem como a autonomia do ponto de vista motor e a cooperação entre as crianças. 
O "pega e puxa" foi um jogo realizado no qual a regra era tentar pegar (agarrar) e puxar o colega pela vestimenta, movendo o oponente para o seu lado da linha demarcada no solo. Destaca-se que, inicialmente, o estagiário deixou essa tarefa livre, ou seja, as crianças poderiam explorar as diversas formas de pegar e puxar, com o objetivo de desequilibrar o colega. Somente após essa vivência inicial, foi sugerida para as crianças a regra do "jogo", qual seja, a de que só poderiam agarrar o colega pela gola ou manga da vestimenta, aproximando-se do gesto motor das lutas. Nesta atividade introduzimos um elemento novo no cerimonial de cumprimento das lutas. Assim, em duplas, as crianças deveriam cumprimentar o seu 'oponente' antes e depois do jogo, identificando e compreendendo a dimensão ética das lutas.

No jogo "a bola é minha" as crianças foram organizadas na área de luta e o estagiário ia formando duplas em que as crianças, uma de frente para a outra com uma bola suíça entre elas. Ao sinal do estagiário, as duas crianças deveriam cumprimentar-se e em seguida agarrarem a bola segurando-a com força. Ojogo inicia depois que os jogadores falarem "a bola é minha". O objetivo desse jogo é retirar a bola dos braços do oponente. Caso, durante a luta, haja desequilíbrio de algum dos jogadores e esse vá ao solo, a luta é pausada. Vence aquela criança que ficar em pé e/ou tomar a bola sem cair. Ao finalizar ojogo, os jogadores devem cumprimentar-se. Nesse momento, foram explorados a oposição e o desequilíbrio como fundamentos das modalidades de lutas, sendo enfocadas habilidades motoras como movimentos de pernas, braços e quadril, que deveriam ser coordenados a fim de atingir o propósito do jogo. Outra estratégia desenvolvida pelo professor, a fim de manter a motivação das crianças, era organizar as duplas com base nas suas características de peso e altura, por exemplo, focalizando um valor intrínseco às lutas, qual seja, o senso de justiça.

Por meio do jogo "pega na cabeça" foi trabalhado outro gesto motor da luta que consiste em ato de ataque e defesa. Nessa atividade, com as crianças organizadas também em duplas e as demais dispostas em círculo, na borda da área de luta, cada uma deveria tentar pegar com a mão na parte superior da cabeça do seu par. Destaca-se que uma das crianças ficava sentada no solo e a outra em pé à sua frente. Ao sinal do estagiário, o jogador que está em pé devia tentar pegar (movimento de ataque) com a mão na parte superior da cabeça daquele que estava sentado, o qual deveria tentar proteger a cabeça, realizando, assim, um movimento de defesa. Vence o jogo aquele que conseguir pegar na cabeça ou, ainda, o jogador que conseguir derrubar o oponente antes de ser tocado ou ficar em pé. Foram propostas, também, situações de inversão dos papéis, para que todos pudessem jogar na posição de pegador e defensor.

Com as intervenções, houve desafios motores e aproximação com o universo dessa prática corporal, que é também um conteúdo da educação física. Ademais, o trato pedagógico desse conteúdo no contexto da educação infantil permitiu trabalhar alguns dos gestos motores em várias modalidades de lutas, bem como aspectos históricos, éticos e morais que constituem esta prática. A abordagem por meio de jogos e brincadeiras 
também permitiu desconstruir a ideia de um ensino das lutas pautado num modelo rígido, tecnicista e excludente, que visa a repetição e a disciplinarização, ampliando as possibilidades de participação e a compreensão das crianças de que os jogos propostos também eram uma forma de luta.

\section{Considerações finais}

O presente relato teve por objetivo descrever uma experiência de ensino que tematizou as lutas na educação física infantil. Por meio dessa experiência, adquirimos e ampliados nossos saberes acerca do trato pedagógico do conteúdo enquanto elemento da cultura corporal, o qual deve ser abordado e problematizado nas aulas de educação física. Apesar do curto espaço de tempo, foi possível proporcionar às crianças a vivência de conteúdos relacionados às lutas, destacando aspectos conceituais, históricos, éticos, bem como o gesto motor presente nas diferentes modalidades, em particular aquelas de agarre e/ou solo. Porém, se houvesse um maior número de intervenções, o aprendizado poderia ser ampliado e outras modalidades de lutas poderiam ser desenvolvidas.

Neste sentido, o estágio apresentou-se como uma oportunidade de nos colocarmos no papel de aprendizes da profissão, abordando um conteúdo pouco explorado no contexto escolar, em particular, na educação infantil. Um desafio nessa experiência diz respeito à falta de materiais para o ensino das lutas, exigindo adaptação dos espaços e materiais da instituição a fim de garantir a segurança na realização das atividades. Por outro lado, a aprendizagem desse conteúdo colocou-se como algo motivante para as crianças e contribuiu para desmistificar paradigmas vigentes relacionados à violência e ao gênero. Outro ponto positivo dessa experiência foi a incorporação pelas crianças de atitudes e valores nas lutas que exigem demonstrações de respeito pelo colega, colaboração, trabalho em equipe, dentre outros.

A utilização do lúdico, bem como a adequação de espaços e materiais apresentou-se como uma possibilidade para tematizar as lutas na educação infantil. Sendo assim, é possível adaptar ambientes e materiais, a fim de manter os cuidados necessários ao trato com crianças de pouca idade, ao mesmo tempo em que proporciona sentido prático entre as lutas e a cultura infantil, sem deixar de fora elementos fundamentais como gestos, movimentos, histórias, tradições, valores morais, éticos etc.

Concluímos, assim, que a educação física se constitui um espaço e tempo para tematizar a cultura corporal na escola, promovendo o contato e ampliação dos conhecimentos das crianças acerca de determinadas práticas corporais. Assim sendo, a proposta do ensino das lutas por meio do jogo e da brincadeira, na educação infantil é possível, mediante adequações, de modo a respeitar as características da instituição e do público por ela atendido, especialmente as crianças. 
Espera-se que essa experiência sirva de motivação para outros professores na organização da sua prática pedagógica, encorajando-os a sistematizarem e compartilharem suas experiências, oferecendo exemplos de como abordar determinados conteúdos no contexto escolar, auxiliando na organização e reflexão da prática docente. Ademais, sugere-se que outras estratégias sejam utilizadas, bem como se trabalhe as diversas modalidades de lutas no cenário da educação infantil e ao longo de todo o processo de escolarização.

Recebido: 11/12/2018 e Aprovado: 06/08/2019

\section{Notas}

1 O referido estágio é realizado no $5^{\circ}$ semestre do curso de Licenciatura em Educação Física do Cefid-Udesc, sempre em instituições públicas de educação infantil.

2 Cada grupo conta com uma professora regente e uma auxiliar. Quando há, no grupo, crianças com deficiência, há mais uma professora auxiliar para acompanhá-la.

3 Tem por objetivo agarrar o oponente conduzindo-o ao solo, podendo dar continuidade ou não, dependendo da modalidade de luta, suas regras, culturas, tradições (judô, jiu-jitsu, dentre outras).

4 Termo de uso popular formado pelas iniciais de Mixed Martial Arts que significa Artes Marciais Mistas, isto é, o uso pelo atleta de técnicas originárias de diversos estilos de lutas (MADURO, 2015).

\section{Referências}

CIRINO, C.; PEREIRA, M. P. V. C; SCAGLIA, A. J. Sistematização dos conteúdos das lutas para o ensino fundamental: uma proposta de ensino pautada nos jogos. Revista Mineira de Educação Física, Viçosa, Edição Especial, n. 9, p. 221-227, 2013.

FARIAS, M. J.; WIGGERS, I. D.; VIANA, R. N. A. O lúdico e a violência nas brincadeiras de luta: um estudo do "se - movimentar" das crianças em uma escola pública de São Luís, maranhão - Brasil. Holos, Natal, Ano 30, v. 5, 2014, p. 98-111.

MADURO, L. A. Considerações e sugestões para o ensino das lutas no ambiente escolar. Cadernos de Formação RBCE, Florianópolis, v. 6, n. 2, p. 60-68, set. 2015.

NASCIMENTO, P. R. B.; ALMEIDA, L. A tematização das lutas na educação física escolar: restrições e possibilidades. Movimento, Porto Alegre, v. 17, n. 3, p. 91-110, set./dez. 2007.

NEIRA, M. G. Práticas corporais: brincadeiras, danças, lutas, esportes e ginásticas. São Paulo: Editora Melhoramentos, 2014. (Como eu ensino).

OLIVIER, J. C. Das brigas aos jogos com regras: enfrentando a indisciplina na escola. Porto Alegre: Artmed, 2000. 
PEREIRA, M. P. V. C., et. al. A contribuição da pedagogia do jogo para o ensino das lutas na educação física escolar. In: $5^{\mathbf{0}}$ Congresso internacional dos jogos desportivos, 2015, UFMG, Belo Horizonte/MG. Disponível em: https://www.researchgate.net/publication/322698671_A_CONTRIBUICAO_ DA_PEDAGOGIA_DO_JOGO_PARA_O_ENSINO_DAS_LUTAS_NA_EDUCACAO_FISICA_ ESCOLAR. Acesso em: 17 de outubro de 2017.

RUFINO, L. G. B. Lutas. In: GONZÁLEZ, F. J.; DARIDO, S. C.; OLIVEIRA, A. A. B. Lutas, capoeira e práticas corporais de aventura. Maringá: Eduem, 2014. p. 29-68. (Práticas corporais e a organização do conhecimento, v. 4).

RUFINO, L. G. B.; DARIDO, S. C. O jiu jitsu brasileiro nas três dimensões dos conteúdos nas aulas de Educação Física escolar. 2009. p. 398-413. Disponível em: https://www.researchgate.net/ publication/280444900_O_jiu_jitsu_brasileiro_nas_tres_dimensoes_dos_conteudos_nas_aulas_ de_Educacao_Fisica_escolar. Acesso em: 04/10/2017. 